\title{
Acoustic targets at South Georgia and the South Orkney Islands during a season of krill scarcity
}

\author{
Andrew S. Brierley*, Jonathan L. Watkins \\ British Antarctic Survey, Natural Environment Research Council, High Cross, Madingley Road, \\ Cambridge CB3 0ET, United Kingdom
}

\begin{abstract}
Dual frequency ( 38 and $120 \mathrm{kHz}$ ) acoustic surveys of shelf-break regions in the vicinity of the Willis Islands, South Georgia, and Coronation Island, South Orkneys, both in the Atlantic sector of the Southern Ocean, were carried out from RRS 'James Clark Ross' during January 1994. The difference in echo signal strength between the 2 frequencies [ $\delta \mathrm{MVBS}$ (mean volume backscattering strength) = MVBS $120 \mathrm{kHz}-$ MVBS $38 \mathrm{kHz}$ ] was used to partition acoustic targets into 3 biological categories: Antarctic krill Euphausia superba, nekton (larger than krill) and zooplankton (smaller than krill). Krill density estimates were derived for both survey areas, and the relative contribution of each class of target to overall regional pelagic biomass determined. Krill distribution in both regions was extremely patchy, resulting in a highly skewed frequency distribution of density; for example one echointegration interval contained $10^{4}$ times the mean krill density. An approximate 6 -fold difference in mean krill abundance was detected between the 2 areas but, in comparison with previously published density estimates, krill densities in both regions were extremely low $\left\{1.7\right.$ and $10.7 \mathrm{gm}^{-2}$ for Willis and Coronation Islands respectively). Gross regional differences in pelagic faunal composition were apparent from inspection of echo charts, and were quantified by detailed analysis of acoustic signals. The water column in the vicinity of the Willis Islands was characterised by a series of diffuse but continuous scattering layers visible only at $120 \mathrm{kHz}$, and $73 \%$ by mass of acoustic targets in this region were classified as zooplankton. In marked contrast, the Coronation Island region was dominated by dense, discrete acoustic target patches which were classified as larger, nektonic, sound scatterers (fish or squid), and only $12 \%$ of targets there were classified as zooplankton. Elsewhere, data from predator diet analyses carried out at Bird Island. South Georgia, during the same season that our acoustic measurements were made, confirm the profoundly low levels of krill availability there and support the acoustic observation that the Willis Islands region contained large numbers of small zooplankton such as the amphipod Themisto gaudichaudii. Similarly, available data on analyses of stomach contents of Chinstrap penguins nesting in a neighbouring region within an oceanographic setting similar to that of Coronation Island reveal the presence of more fish in the diet than usual. Conclusions drawn from acoustic observations as to the relative regional composition of pelagic biomass are therefore clearly supported by independent evidence gathered from predators, and the value of integrating predator/ prey and acoustic studies to characterise the content of localised marine ecosystems is demonstrated.
\end{abstract}

KEY WORDS: Antarctic krill Euphausia superba - Dual frequency acoustic survey - Predators - Penguin diet Themisto gaudichaudii. Target discrimination - Southern Ocean

\section{INTRODUCTION}

Abundance of the Antarctic krill, Euphausia superba Dana, is known to fluctuate markedly in both space and time at a number of scales (Priddle et al. 1988, Siegel 1988, McClatchie et al. 1994). Notwithstanding these scales of variability, the 1993/94 austral summer has

·E-mail: a.brierley@bas.ac.uk been reported as a season characterised by profound krill scarcity around South Georgia, the South Orkney Islands and the Antarctic Peninsula (Brierley \& Watkins 1995a, b, CCAMLR 1995, Siegel \& Loeb 1995). At South Georgia foraging performance and breeding success of a suite of seabird and seal predators usually dependent on krill was, overall, the worst this decade and, for some species, the worst since records began in 1976 (Croxall et al. 1988, J. P. Croxall, P. A. Prince \& K. Reid in 


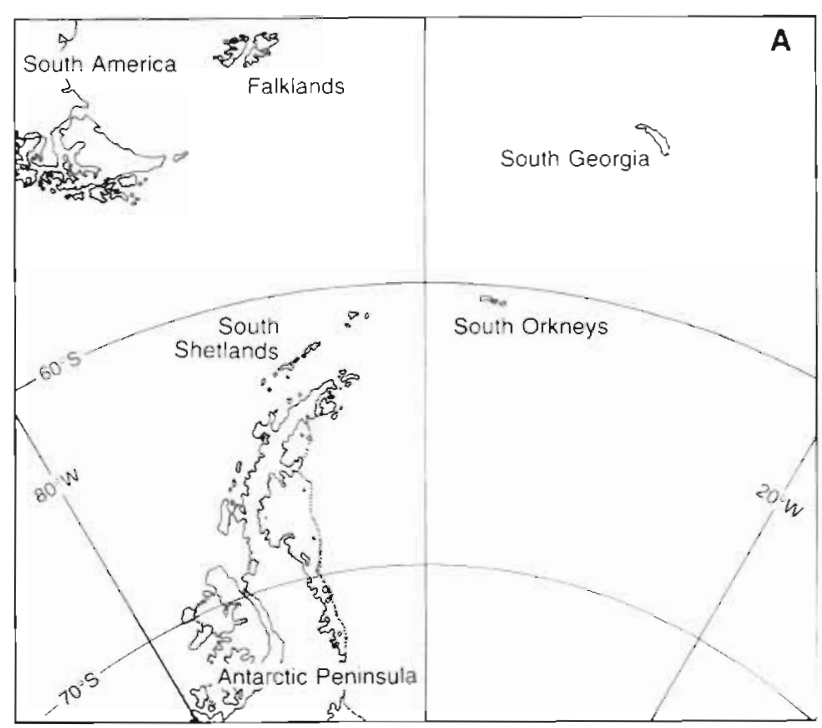

Fig. 1. (A) Locations of South Georgia, the South Orkneys and the South Shetland Islands in the Atlantic sector of the Southern Ocean, with localised details of survey grid layouts near (B) the Willis Islands on the western tip of South Georgia and (C) Coronation Island. Locations of the predator diet sampling sites, Bird Island (B) and Signy Island (C), are also shown

press, unpubl. data). Similar data from Signy Island, South Orkneys, indicated that penguin breeding success was poor but better than at South Georgia (CCAMLR 1995, J. P. Croxall \& S. Brockington unpubl. data).

Acoustic techniques have for some time been used to estimate krill biomass in the Southern Ocean (FIBEX 1980, Everson 1983, Everson \& Miller 1994, Trathan et al. 1995). Inspection of characteristic markings on echo charts has facilitated the visual separation of echo traces caused by krill targets from those caused by fish or zooplankton (for example, Madureira et al. 1993a). Furthermore, analysis of data collected concurrently at 120 and $38 \mathrm{kHz}$ has enabled acoustic signals to be attributed to specific target size and species classes on the basis of the decibel $(\mathrm{dB})$ difference between signals (Madureira et al. 1993b), and has hence provided a means for total observed biomass to be partitioned into various faunal categories

Here dual-frequency acoustic data gathered during surveys around the Willis Islands, South Georgia, and Coronation Island, South Orkneys, both in the Atlantic
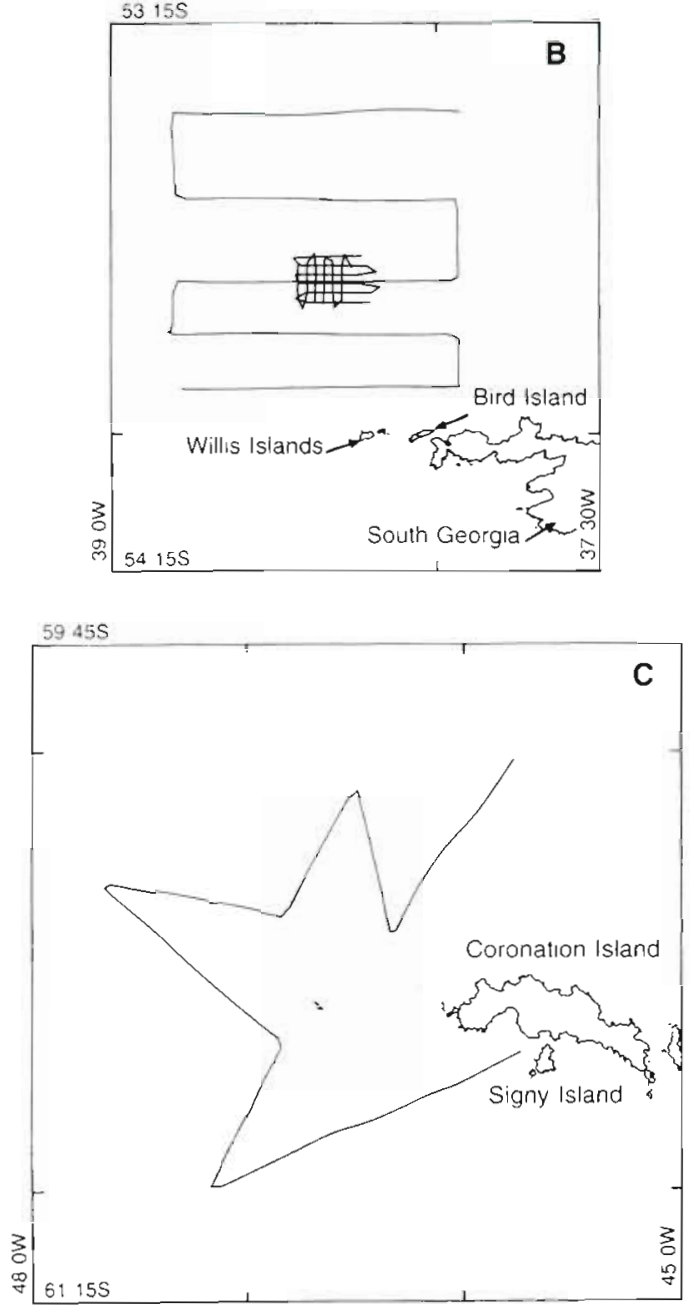

sector of the Southern Ocean (see Fig. 1), are analyzed in an attempt to characterise the composition of pelagic faunal communities, and to quantify the contributions of 3 broad faunal size spectra (Antarctic krill, nektonic species larger than krill, and zooplankton smaller than krill) to overall pelagic biomass at the 2 locations in this atypical season. The results of this analysis are further discussed in light of observations of breeding success and stomach content of a number of habitual krill predator species (CCAMLR 1995, J. P. Croxall et al. unpubl. data) which come ashore to reproduce in these regions. Various parameters describing breeding success and dietary components of several Antarctic mammalian and avian species are regularly monitored (Croxall et al. 1988, Croxall 1993) and provide indices describing the state of the local marine ecosystem (Croxall et al. 1988), including indications of relative prey stock abundance (Croxall 1989, Reid \& Arnould 1996), for input into the Ecosystem Monitoring Program of the Commission for the Conservation of Antarctic Marine Living Resources (CCAMLR). 


\section{MATERIALS AND METHODS}

Acoustic surveys. Acoustic surveys were carried out around the Willis and Coronation Islands from the RRS 'James Clark Ross' during January 1994 using a Simrad EK500 scientific echo-sounder and hullmounted 38 and $120 \mathrm{kHz}$ transducers. Survey transects at both locations encompassed shelf break areas and at each location were surveyed over a continuous period incorporating both day and night. Fig. 1 shows the layout of survey transects at the 2 locations and Table 1 provides information on survey start and end times, distance run and overall area covered by each survey. The Willis Islands survey incorporated both small- and large-scale grids. The 2 small-scale grids were positioned over a sea mount where elevated numbers of krill-like targets had been observed during the preceding large-scale survey, and were surveyed on consecutive days $(24 \mathrm{~h}$ between respective start times), providing an opportunity to investigate the temporal stability of biomass estimation. The survey around Coronation Island was performed opportunistically and was implemented with the intention of maximising areal coverage in a short period of time.

Standard-sphere echo-sounder calibrations (Foote et al. 1987) were carried out before and after the transect surveys, on 7 January and 17 February respectively, at Leith Harbour, South Georgia.

Mean volume backscattering strength (MVBS) data were collected for both frequencies in $2 \mathrm{~m}$ depth horizons between 10 and $250 \mathrm{~m}$ (depths relative to the transducers) at an echo integration threshold of $-100 \mathrm{~dB}$, over time periods (integration intervals) typically of $3 \mathrm{~min}$ duration (approximately $1 \mathrm{~km}$ ) at the Willis Islands and of 1 min duration (approximately $0.3 \mathrm{~km}$ ) at Coronation Island. Integrated data were recorded simultaneously over the serial and ethernet ports to PC and UNIX computing systems respectively. Data were collected with the EK500 noise margin switched off (Simrad 1992) because of the unquantifiable effect this function has on the signal passed for processing Background noise amplified by a time-varied gain (TVG) function, used to compensate for increased signal spreading and attenuation with increased water depth, was removed using the technique described by Watkins \& Brierley (1996) which was implemented via a series of customised Application Visualization System modules (Socha et al. 1996). Further signal post-processing was also required to counter the effects of numerous software faults encountered in version 3.01 of the EK500 software (Watkins et al. 1995), and was carried out using a number of purpose-written Genstat (Payne et al. 1993) procedures.

Echo identification. Clearly, even at times of high krill abundance, not all acoustically detected targets in the water column will be krill. Madureira et al. (1993a) described the use of the difference in mean volume backscattering strength between 120 and $38 \mathrm{kHz}$ signals ( $\delta$ MVBS $=$ MVBS $120 \mathrm{kHz}-$ MVBS $38 \mathrm{kHz}$ ) to distinguish echoes caused by different size classes of biological scatterers in the Southern Ocean. In a refinement of this technique, incorporating additional information describing the differences in $\delta$ MVBS for 3 Antarctic macroplankton species (Madureira et al. $1993 b$ ), the following criteria were used here to partition acoustic data into 3 biological categories: $\delta M V B S$ between 2.5 and $6 \mathrm{~dB}$, Antarctic krill; $\delta \mathrm{MVBS}$ between 6 and $20 \mathrm{~dB}$, zooplankton smaller than krill; $\delta \mathrm{MVBS}$ between -20 and $2.5 \mathrm{~dB}$, nektonic organisms larger than krill.

Krill length estimation. A number of net hauls were taken around the Willis Islands in an attempt to determine a mean krill length for the region. Nets used were a rectangular midwater trawl (RMT, mouth opening $25 \mathrm{~m}^{2}$ ), a fore-deck frame net (FNET, mouth opening $\left.1 \mathrm{~m}^{2}\right)$ and a horizontal Antarctic multiple plankton sampler (HAMPS, mouth opening $2 \mathrm{~m}^{2}$ ). Constraints on time prevented net sampling at Coronation Island. In order to derive a length estimate for krill around Coronation Island, all acoustic data from that region classified as originating from krill (i.e. where $\delta$ MVBS was between 2.5 and $6 \mathrm{~dB}$ ) were analyzed using an algorithm which relates krill length to the difference in signal strength at 120 and $38 \mathrm{kHz}$ (Mitson et al. 1996). An estimate for the Willis Islands was similarly calculated for comparative purposes.

Target strength (TS). Target strength $(\mathrm{dB})$ is a measure of the magnitude of the echo returning from a target relative to the strength of the transmitted acoustic signal, and is the factor used to convert observed echo strength into biomass (MacLennan \& Simmonds 1992). Target strength varies between species, and within species is affected by a number of factors including target size. A common practical measure of size used by fisheries biologists is target length, and target strength

Table 1. Euphausia superba. Survey start and end times distance run on transect (length, $\mathrm{km}$ ), and overall area covered by each survey $\left(\mathrm{km}^{2}\right)$ in 1994

\begin{tabular}{|lrcrr|}
\hline Survey & Start & End & Length & Area \\
\hline Willis Islands, large & 9 Jan, 11:33 & 10 Jan, 05:42 & 254.48 & 4200 \\
Willis Islands, small 1 & 10 Jan, 08:27 & 10 Jan, 13:57 & 89.02 & 170 \\
Willis Islands, small 2 & 11 Jan, 09:40 & 11 Jan, 13:37 & 62.96 & 130 \\
Coronation Island & 22 Jan, 20:54 & 23 Jan, 16:17 & 319.71 & 7200 \\
\hline
\end{tabular}


relationships are often expressed in terms of target length (Foote 1987). The currently recommended (CCAMLR 1991) TS to length relationship for Antarctic krill is that of Greene et al. (1991):

$$
\operatorname{TS}(\mathrm{dB})=-127.45+34.85 \times \log _{10} \text { length }(\mathrm{mm})
$$

Although, as Fig. 2 illustrates, the TS of an individual krill increases rapidly with increasing length, the mean volume backscattering strength of a biomass of numerous krill is much less influenced by variations in lengths of the individuals contributing to that biomass. As Hewitt \& Demer (1993) pointed out, this is because the number of krill of a given length required to yield a given biomass decreases at approximately the same rate at which the backscattering cross-section of an individual krill increases with length. The backscattering cross-section $\sigma_{b s}$ is the important physical dimension determining the magnitude of an echo returning from a target (Clay \& Medwin 1977).

The implication of these relationships is that the target strength of a given biomass of krill, say $1 \mathrm{~kg}$, is a robust concept little affected by krill length, and this measure was consequently used here to determine krill biomass values for the 2 study locations. We derived a generic krill TS to biomass relationship in accordance with Hewitt \& Demer (1993) as follows. The relationship

$$
\text { wet mass }(\mathrm{g})=3.85 \times 10^{-6} \times \text { length } \mathrm{h}^{3.2}(\mathrm{~mm})
$$

(Morris et al. 1988) was used to estimate the number of individual krill of a given size required to yield $1 \mathrm{~kg}$ of krill. The MVBS at $120 \mathrm{kHz}$ which would be observed if that number of krill per cubic metre were insonified was then calculated by rearranging

$$
\text { density }=\operatorname{antilog}_{10}[(\mathrm{MVBS} 120 \mathrm{kHz}-\mathrm{TS}) / 10]
$$

(see MacLennan \& Simmonds 1992), using a target strength value for each size fraction derived from the (CCAMLR 1991) recommended relationship (Greene et al. 1991; Eq. 1). Fig. 2 illustrates the product of this derivation. Finally a mean value for krill within the size range of 25 to $55 \mathrm{~mm}$, a realistic range chosen on the basis of numerous years of field experience within British Antarctic Survey, was calculated, yielding a target strength for $1 \mathrm{~kg}$ of krill of $-38.77 \mathrm{~dB}$.

Data analysis. A krill target strength of $-38.77 \mathrm{~dB}$ $\mathrm{kg}^{-1}$ was applied to all noise-corrected, $-100 \mathrm{~dB}$ thresholded $120 \mathrm{kHz}$ values using a Genstat (Payne et al. 1993) procedure, converting MVBS into biomass $\left(\mathrm{kg} \mathrm{m}^{-3}\right)$ per $2 \mathrm{~m}$ depth horizon per reset. These biomass values, along with their associated 120 and $38 \mathrm{kHz}$ MVBS values, were loaded into an Oracle database. This facilitated the subsequent selection of data points on the basis of $\delta$ MVBS, and thus allowed targets to be easily partitioned into faunal classes using the

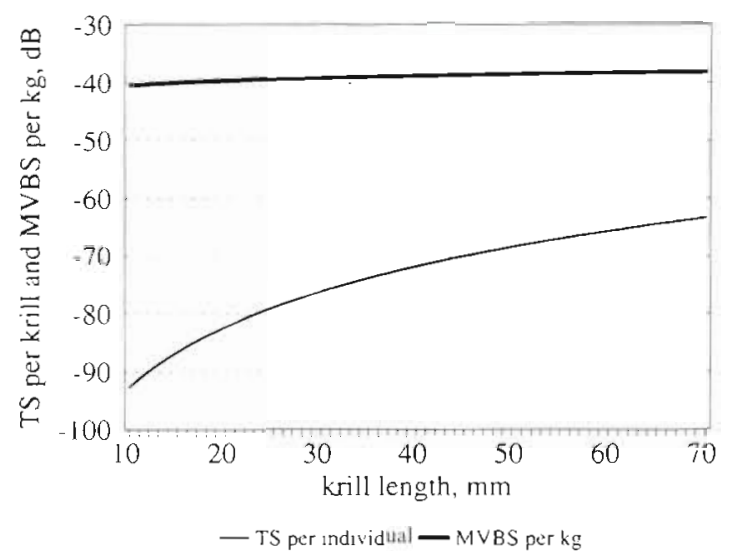

Fig. 2. Euphausia superba. Relationships between length of an individual krill and target strength (TS), and mean volume backscattering strength (MVBS) per $\mathrm{kg}$ of krill of a given length against krill length

criteria outlined above. All density values $\left(\mathrm{kg} \mathrm{m}^{-3}\right)$ from $2 \mathrm{~m}$ depth horizons within a reset meeting the selection criteria were multiplied by 2 to account for horizon depth, summed, and the within-reset total multiplied by reset length $(\mathrm{km})$ to give a total density for each reset. Reset totals were summed within transects and divided by total transect length $(\mathrm{km})$ to yield a mean transect density in $\mathrm{kg} \mathrm{m}^{-2}$ (Jolly \& Hampton 1990).

Geostatistical analysis, arguably the most appropriate statistical technique for determination of biomass from acoustic data collected from non-random surveys (Simmonds et al. 1992, Petitgas 1993), was attempted on the Willis Islands data using the software packages EVA (Petitgas \& Prampart 1993) and Genstat (Payne et al. 1993). The extreme spatial patchiness of target distribution however prevented construction of meaningful variograms, a problem which has previously been encountered with Antarctic krill data sets (Murray 1996). Given such apparently random target distribution, it is reasonable to consider that the transects steamed were essentially random with reference to the underlying spatial distribution of targets (Murray et al. 1995), and consequently a valid calculation of variance can be made even though the transects were essentially not positioned randomly. The 5 mean transect densities from the Willis Islands large-scale grid survey were accordingly analyzed following the method of Jolly \& Hampton (1990), and weighted mean and variance estimates were derived. The 7 transects comprising the star-shaped survey around Coronation Island were also considered as if randomly located. Star-shaped designs however suffer from effective over-sampling in the vicinity of convergent transect lines. To overcome this problem the entire Coronation Island krill data set was first subject to analysis of autocorrelation using a Genstat (Payne et al. 1993) proce- 
dure. This analysis revealed that there was no significant autocorrelation of target density distribution beyond 5 lag intervals, i.e. beyond approximately $1.5 \mathrm{~km}$. Consequently convergent survey transects were truncated to prevent transects encroaching beyond a minimum separation distance of approximately $2.5 \mathrm{~km}$. Truncated Coronation Island transects were then similarly analyzed according to Jolly \& Hampton (1990).

In order to investigate spatial interactions between krill and its predators, the Willis Islands small-scale surveys were specifically positioned in a region where elevated krill densities had been observed previously (Hunt et al. 1992, Veit et al. 1993, R. R. Veit pers. comm. 1994). Such adaptive surveys are not random, and cannot be considered representative of the region as a whole (MacLennan \& Simmonds 1992). However, as the 2 small-scale surveys essentially covered the same area, they provided an opportunity to investigate the effect of temporal variation on biomass estimation. Weighted survey means were calculated as for the 2 large-scale surveys, and a straightforward variance of the mean for the 2 small-scale repeat surveys was subsequently derived.

\section{RESULTS}

Examination of the echo charts from the Willis Islands grids revealed the presence of occasional dense, localised acoustic targets dispersed amongst persistent but diffuse scattering layers which were detected only at $120 \mathrm{kHz}$. Such diffuse scattering layers were absent over the majority of the Coronation Island grid, targets there appearing almost exclusively as discrete, dense aggregations visible at both frequencies. This gross difference in regional acoustic character is highlighted by the shift in modal $\delta$ MVBS in the $\delta$ MVBS frequency distribution within sites (Fig. 3). This shows a larger proportion of data points from the Willis Islands surveys falling into the $\delta \mathrm{MVBS}$ $>6 \mathrm{~dB}$ (zooplankton) range, whereas around Coronation Island data from relatively more depth/reset cells lie within the $\delta$ MVBS $<2.5 \mathrm{~dB}$ (nekton) category, Less than $3 \%$ of all observed echo signal pairs fell outside the defined $d B$ ranges used to separate the 3 faunal categories. Target fishing carried out at several locations during the course of the cruise confirmed that the SMVBS range 2.5 to $6 \mathrm{~dB}$ was appropriate for the segregation of krill targets.

Mean lengths of krill retained by each of the 3 nets around the Willis Islands are given in Table 2. Lengths calculated using the algorithm of Mitson et al. (1996) for krill in both regions are given in Table 3 .

Using the derived target strength of $-38.77 \mathrm{~dB} \mathrm{~kg}^{-1}$ krill, mean krill densities of 1.73 and $10.65 \mathrm{~g} \mathrm{~m}^{-2}$ were

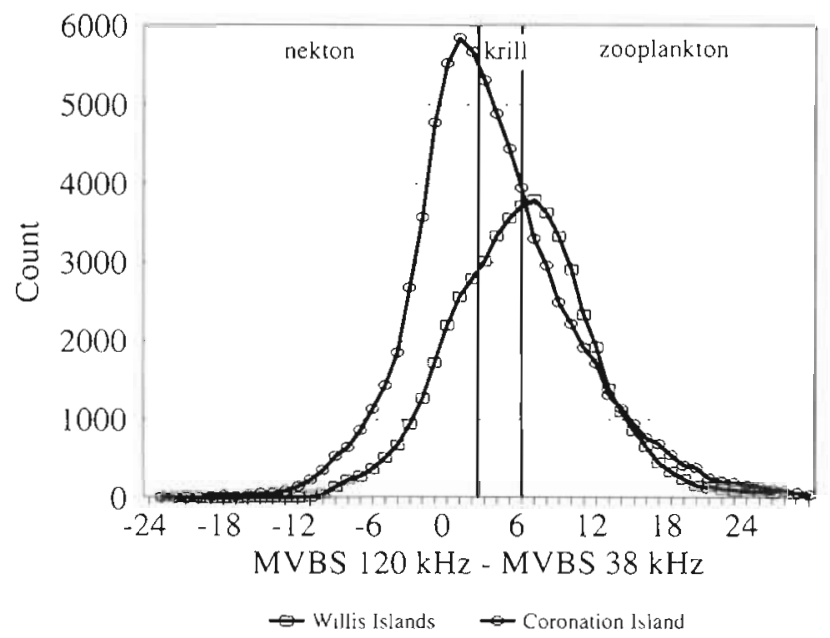

Fig. 3. $\mathrm{MVBS}$ (MVBS $120 \mathrm{kHz}$ - MVBS $38 \mathrm{kHz}$ ) frequency distributions for acoustic targets at the 2 survey locations. Vertical lines mark $\delta$ MVBS boundaries between the 3 putative biological classes of scatterers

calculated for the Willis and Coronation Islands respectively. Densities for each class of scatterer at each location are presented in Table 4 . The relative proportions of the 3 putative biological classes of scatterers at each site are presented schematically in Fig. 4. Biomass estimates can be attached to the small zooplankton component at each site as the generic target strength relationship is likely to approximate a plausible TS value for a heterogeneous aggregation of small

Table 2. Euphausia superba. Mean size of krill retained by rectangular midwater trawl (RMT), fore-deck frame net (FNET) and horizontal Antarctic multiple plankton sampler (HAMPS) during hauls around the Willis Islands. Numbers in parentheses are SE

\begin{tabular}{|lc|}
\hline Net & Mean krill size, $(\mathrm{mm})$ \\
\hline RMT & 48.07 \\
& $(0.42)$ \\
FNET & 37.49 \\
& $10.56)$ \\
HAMPS & 45.94 \\
& $(2.33)$ \\
All pooled & 45.48 \\
\hline
\end{tabular}

Table 3. Euphausia superba. Mean krill length at each 10cation calculated using the frequency difference algorithm (Mitson et al. 1996)

\begin{tabular}{|lc|}
\hline Location & Calculated krill length $(\mathrm{mm})$ \\
\hline Signy Island & 35.21 \\
Willis Islands & 35.86 \\
All pooled & 35.53 \\
\hline
\end{tabular}



estimates for each faunal size class at each location

\begin{tabular}{|c|c|c|c|c|c|}
\hline \multirow[t]{2}{*}{ Survey } & \multirow{2}{*}{\multicolumn{2}{|c|}{ Transect Length $(\mathrm{km})$}} & \multicolumn{3}{|c|}{ Mean density $\left(\mathrm{g} \mathrm{m}^{-2}\right)$} \\
\hline & & & Krill & Zooplankton & Nekton \\
\hline \multirow[t]{7}{*}{ Willis, large } & 1 & 30.19 & 1.82 & 4.27 & 1.79 \\
\hline & 2 & 56.01 & 1.51 & 3.46 & 1.78 \\
\hline & 3 & 56.73 & 3.01 & 11.81 & 1.03 \\
\hline & 4 & 55.21 & 1.12 & 10.16 & 1.00 \\
\hline & 5 & 56.34 & 1.23 & 9.36 & 1.37 \\
\hline & \multicolumn{2}{|c|}{ Weighted mean } & 1.73 & 8.18 & 1.35 \\
\hline & \multicolumn{2}{|l|}{ Variance } & 0.14 & 2.75 & 0.03 \\
\hline \multirow[t]{7}{*}{ Willis, small 1} & 1 & 13.91 & 3.26 & 16.38 & 1.73 \\
\hline & 2 & 13.08 & 3.05 & 9.96 & 1.22 \\
\hline & 3 & 15.67 & 2.46 & 8.49 & 1.80 \\
\hline & 4 & 15.87 & 1.96 & 8.89 & 1.27 \\
\hline & 5 & 14.43 & 1.50 & 11.69 & 0.78 \\
\hline & 6 & 16.05 & 1.68 & 24.36 & 3.92 \\
\hline & \multicolumn{2}{|c|}{ Weighted mean } & 2.29 & 13.39 & 1.83 \\
\hline \multirow[t]{8}{*}{ Willis, small 2} & 1 & 8.98 & 2.47 & 13.43 & 0.86 \\
\hline & 2 & 9.77 & 3.49 & 6.71 & 1.70 \\
\hline & 3 & 10.63 & 3.52 & 7.00 & 2.24 \\
\hline & 4 & 10.21 & 6.45 & 3.15 & 4.46 \\
\hline & 5 & 9.79 & 11.66 & 6.08 & 7.57 \\
\hline & 6 & 10.46 & 16.68 & 8.97 & 28.43 \\
\hline & 7 & 3.12 & 4.37 & 4.55 & 5.36 \\
\hline & \multicolumn{2}{|c|}{ Weighted mean } & 7.34 & 7.31 & 7.65 \\
\hline \multirow[t]{9}{*}{ Coronation } & 1 & 80.23 & 4.47 & 2.01 & 17.12 \\
\hline & 2 & 30.05 & 3.43 & 3.87 & 4.54 \\
\hline & 3 & 50.44 & 2.82 & 3.79 & 4.54 \\
\hline & 4 & 41.47 & 12.54 & 12.34 & 11.11 \\
\hline & 5 & 29.88 & 7.38 & 4.49 & 7.83 \\
\hline & 6 & 33.53 & 24.19 & 3.35 & 72.62 \\
\hline & 7 & 54.12 & 23.06 & 4.49 & 46.47 \\
\hline & \multicolumn{2}{|c|}{ Weighted mean } & 10.65 & 4.60 & 23.10 \\
\hline & \multicolumn{2}{|c|}{ Variance } & 12.80 & 1.71 & 71.09 \\
\hline
\end{tabular}

Table 4. Mean transect densities, and weighted survey mean and variance

crustacean zooplankters. In the absence of any other appropriate general TS value for the nektonic fraction, which was likely to be composed of fish with and without swim bladders and of various squid species, the generic TS value was applied here also, Although a biomass estimate cannot be attached to this proportion with any degree of confidence, the measure is useful to the extent that it provides a comparable indication of the relative abundance of this pelagic size fraction at each location. This approach essentially has the effect of scaling all backscattering density values by a common factor, and could be considered in broad terms as portraying densities in units of equivalent krill biomass.

Separate weighted variance estimates for the 2 small Willis Islands grid surveys are not given since, as Jolly \& Hampton (1990) point out, a valid estimate of sampling variance cannot be made if transects are not randomly selected. These 2 grids can however be considered as repeat samples of a single location and, on this basis, a variance of the mean krill density between samples was calculated as 6.37

\section{DISCUSSION}
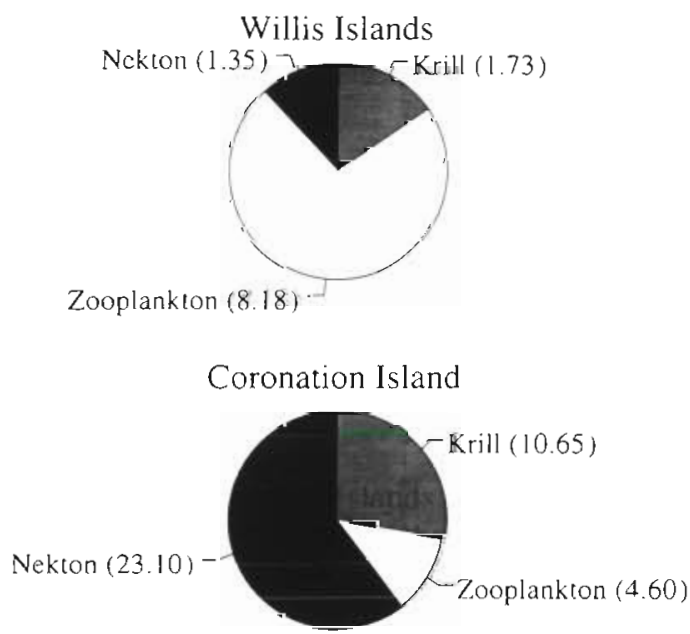

Fig. 4. Relative proportions and mean densities $\left(\mathrm{g} \mathrm{m}^{-2}\right)$ of the 3 putative biological classes of scatterers, krill, zooplankton and nekton, at the 2 survey locations
Initial examination of echo charts from the 2 survey regions revealed obvious differences in acoustic characteristics, the predominance of diffuse $120 \mathrm{kHz}$ scattering layers at Willis Islands providing the first indication of a relatively high proportion of small scatterers there (see Figs. 3 \& 4). Further detailed analysis has confirmed that a marked difference in pelagic faunal composition and overall total biomass existed between the water columns around Willis and Coronation Islands at the time these surveys were carried out. Krill densities around Coronation Island were of the order of 6 times those observed during the large-scale Willis Islands grid, although they appear to be more similar to densities observed during the small Willis Islands survey grids. These small-scale grids were centred over a sea mount, features which than that found in the surrounding open ocean (Rogers 1994), in an area where elevated krill concenare generally associated with higher pelagic biomass 
trations have been observed during previous cruises (D. R. R. Veit pers, comm.). Krill distributions were extremely patchy in both regions, one reset for example containing 100 times the mean krill density for all resets. Furthermore one reset on an inter-transect link of the Willis Islands large-scale grid contained $10^{4}$ times the mean density per reset for the transects included in the statistical analysis. These data, and all other data from inter-transect links, were discarded for the purposes of quantitative analysis, as required by the method of Jolly \& Hampton (1990), but serve to emphasise the extremely patchy nature of krill distribution and the problems associated with sampling mobile resources such as krill (e.g. Kanda et al. 1982). Such patchiness may perhaps be particularly marked during times of krill scarcity if krill attempt to maintain individual swarm densities, with a consequent reduction in the total number of swarms in a given area. Caution should therefore be exercised in interpretation of perceived regional differences in krill densities reported here.

The problem of geographic variability is compounded in a mobile resource such as krill by temporal variation (see for example McClatchie et al. 1994, Murray et al. 1995). The considerable difference in mean krill density estimates between the 2 small Willis Islands grids (2.29 and $7.34 \mathrm{~g} \mathrm{~m}^{-2}$; see Table 4) illustrates this point, although small sample size and the associated high between-survey variance estimate make it difficult to draw inferences from statistical comparisons between times. The phenomenon of temporal variation has implications for the development of representative and effective survey design and krill sampling strategy (see MacLennan \& Simmonds 1992). A further aspect of temporal variation is diel vertical migration, a behavioral trait which is well documented for a large number of zooplankton species (see for example Gliwicz 1986) including krill (Godlewska \& Klusek 1987). Surveys reported here incorporated periods of both day and night, and it is therefore unlikely that the overall low density estimates obtained are solely as a result of bias arising from the migration of krill into the acoustically blind upper regions of the water column during hours of darkness (see Everson 1983, Demer \& Hewitt 1995).

Both the net haul and dB-difference approaches to mean krill length estimation taken here are subject to potential sources of error. Net selectivity can result in catch bias (reviewed by Clutter \& Anraku 1968, see also Wiebe et al. 1982, Hovekamp 1989), as is clearly demonstrated here for example by the difference in mean krill size retained by the FNET and RMT (see Table 2). The acoustic approach using the dB-difference algorithm (Mitson et al. 1996) suffers from the a priori requirement for preselecting acoustic data likely to be representative of krill. Although it has been demonstrated that the algorithm yields size estimates for Euphausia superba very similar to those obtained from net hauls where accurate target fishing of discrete swarms has allowed direct comparisons to be made (Mitson et al. 1996), in the absence of direct support from net hauls, changing the criteria ( $\delta$ MVBS) on which echoes are ascribed to krill will inevitably change the resultant mean length estimate. The fact that at the Willis Islands net and calculated length estimates differ by approximately $10 \mathrm{~mm}$ illustrates the problem of obtaining precise length estimates, and casts doubt on the accuracy of both methods. A difference in individual krill length of $9.6 \mathrm{~mm}$, as seen here between the mean krill length estimate derived from net hauls around the Willis Islands $(45.48 \mathrm{~mm})$ and the acoustically determined estimate for the same region (35.86 mm), would, from Eq. (1) (Greene et al. 1991), result in a TS change of more than $3.6 \mathrm{~dB}$. A TS change of this magnitude is equivalent to a change in perceived target density by a factor of 2.3 , and such a difference is therefore substantial. The derived generic TS relationship however greatly reduces the dependence of TS on estimates of individual krill length, and therefore reduces this potential source of error (Hewitt $\&$ Demer 1993) to biomass estimation. For example the length difference of $9.6 \mathrm{~mm}$ outlined above results in a change in generic TS of only $0.3 \mathrm{~dB}$, which in turn equates to a maximum potential biomass discrepancy of only $7 \%$. The generic target strength allows directly comparable biomass estimates to be calculated when uncertainties surround target length-frequency distributions, and also serves to compensate to some extent for variations which could result from size heterogeneity between individuals within single krill aggregations (Watkins 1986, Watkins et al. 1986, 1990). On this occasion the dB-difference algorithm (Mitson et al. 1996) produced a mean krill length estimate for both Willis and Coronation Islands of the order of $35 \mathrm{~mm}$, and this provides further justification for using the same mean generic krill TS value for both regions. The TS per $\mathrm{kg}$ value of $-38.77 \mathrm{~dB}$ is approximately $1 \mathrm{~dB}$ lower than that previously used by Hewitt \& Demer (1993). This discrepancy is due solely to the choice of krill wet mass to length relationship. Increasing the TS used here by $1 \mathrm{~dB}$ to the value advocated by Hewitt \& Demer (1993) would serve to further decrease perceived krill biomass (by approximately $25 \%$ ), further emphasising the paucity of krill in the 1993/94 austral summer season. Such an increase would not however alter the way in which observed acoustic targets were partitioned into their relative faunal classes.

Analysis of acoustic data from the present study was made unusually arduous because of a number of EK500 software flaws (see Watkins et al. 1995, Watkins 
\& Brierley 1996). Target identification may have been compromised at depths below $100 \mathrm{~m}$ (see Watkins \& Brierley 1996), with some targets yielding SMVBS values close to those separating the different classes of scatterers perhaps being partitioned erroneously. This effect is likely to have been manifested to the same degree at each location, and our conclusions on the differing relative abundance of target classes between sites therefore remain valid. Since the majority of targets were observed above $100 \mathrm{~m}$, however, the effect of this on assessment of absolute biomass is likely to have bcon negligeable.

Despite the difficulties outlined above, the data reported here clearly show that, in comparison to previously recorded density estimates (for example McClatchie et al. 1994, Trathan \& Everson 1994, Murray et al. 1995, Trathan et al. 1995; Table 5), krill densities in both regions were exceptionally low at the time these acoustic surveys were undertaken. Further evidence for the very low prevailing krill abundance during this summer is provided by diet composition and levels of breeding success of birds and seals in the area. The reproductive performance of selected avian and mammalian species is monitored annually at Bird Island, South Georgia, and at Signy Island, South Orkney Islands, together with annual monitoring of

Table 5. Euphausia superba. Krill densities observed during this and previous studies

\begin{tabular}{|c|c|c|}
\hline Location & Krill biomass $\left(\mathrm{g} \mathrm{m}^{-2}\right)$ & Source \\
\hline South Georgia & 59.7 & $\begin{array}{l}1981 \text { survey } \\
\text { Trathan \& Everson (1994) }\end{array}$ \\
\hline South Orkneys & 82.8 & $\begin{array}{l}1981 \text { survey } \\
\text { Trathan \& Everson (1994) }\end{array}$ \\
\hline Elephant Island & 11 to 20 & $\begin{array}{l}1990 \text { survey } \\
\text { McClatchie et al. (1994) }\end{array}$ \\
\hline Bellingshausen Sea & 19.6 to 42.0 & $\begin{array}{l}1992 \text { survey } \\
\text { Murray et al. (1995) }\end{array}$ \\
\hline Willis Island & 1.73 & This study \\
\hline Coronation Island & 10.65 & This study \\
\hline
\end{tabular}

predator diet at Bird Island (Croxall et al. 1988). In the $1993 / 94$ season krill formed only $9 \%$ by mass of the diet of Gentao penguins at Bird Island, compared to a mean of $61 \%$ measured over a 13 season period between $1976 / 77$ and 1994/95; in the same season an overall breeding success for this penguin species of only $4 \%$ was recorded compared to a mean of $42 \%$ for an 18 season period between 1976/77 and 1994/95 (see Croxall \& Rothery 1995). Antarctic fur seal diet contained more fish (and more species) than usual, although krill was still prevalent (Reid \& Arnould 1996). However fur seal foraging trip duration was in excess of $14 \mathrm{~d}$, compared to a mean of $4.6 \mathrm{~d}$ (data from 10 seasons between 1983/84 and 1992/93; I. L. Boyd \& J. P. Croxall unpubl, data), and pup mortality was, at $>65 \%$, the highest ever recorded $(10$ season mean between 1983/84 and 1992/93 = 23\%) (Boyd et al. 1995): surviving pups had the lowest weaning mass recorded in $20 \mathrm{yr}$ of data (Boyd \& Croxall unpubl. data)

The predator diet analysis at Bird Island has further revealed that some predators, such as the Macaroni penguin and Antarctic prion, which forage abundantly in the region covered by the Willis Islands surveys and which under normal circumstances preferentially target krill as a food source (Croxall et al. 1988, Liddle 1994), switched in 1994 to smaller zooplankters including the amphipod Themisto gaudichaudii and copepod Rhincalanus gigas respectively. Acoustic data reported here suggest that around the Willis Islands zooplankters of this size range were highly abundant (see Table 4 \& Fig. 4). Themisto gaudichaudii is known to have an extremely patchy distribution (Kane 1966, Atkinson 1990), with densities on occasion becoming locally very high. This species seems to offer a viable food alternative to krill for predator species with the ability to exploit it efficiently. For example, over an 11 season period between 1976/77 and 1994/95 Macaroni penguin diet comprised a mean of $83 \%$ krill by mass; Macaroni penguins achieved a mean breeding success of

Table 6. A comparison of mean penguin diet composition and breeding success during (a) several seasons (numbers in parentheses) between 1976/77-1994/95, with those observed during (b) 1993/94. Other includes primarily the zooplankter Themisto gaudichaudit

\begin{tabular}{|c|c|c|c|c|}
\hline & Krill & $\begin{array}{l}\text { position } \\
\text { Fish }\end{array}$ & Other & Breeding success $\%$ \\
\hline (a) Macaroni penguins & $83(11)$ & $5(11)$ & $12(11)$ & $47(19)$ \\
\hline Gentoo penguins & $61(13)$ & $39(13)$ & $<1(13)$ & $42(18)$ \\
\hline (b) Macaroni penguins & 13 & 15 & 71 & 46 \\
\hline Gentoo penguins & 9 & 86 & 4 & 4 \\
\hline
\end{tabular}


$47 \%$ during this time (over 19 seasons between 1976/77 and 1994/95, Croxall et al. unpubl. data). During the 1993/94 season however krill comprised only $13 \%$ by mass of the diet of Macaroni penguins, but these penguins nevertheless managed a $46 \%$ breeding success because they were able effectively to switch to eating Themisto gaudichaudil and other small zooplankton, which in this season made up $71 \%$ by mass of their diet (see Table 6). Data from previous years of reduced krill in predator diets indicate that only Macaroni penguins seem to have the ability to effectively target Themisto gaudichaudii, Antarctic fur seals and Gentoo penguins tending in contrast to switch from krill towards fish.

At Signy Island, close to Coronation Island (Fig. 1), monitoring studies have shown that during most years Adélie and chinstrap penguins almost exclusively eat krill during the breeding season (White \& Conroy 1975, Lishman 1985, Trivelpiece et. al. 1987). Mean breeding successes for these species over the period $1976 / 77$ to $1991 / 92$ were 42 and $57 \%$ respectively (Croxall et al. 1988, Trathan et al. 1996). During the $1993 / 94$ season breeding success fell to $22 \%$ for Adélie penguins and to $19 \%$ for chinstrap penguins (CCAMLR 1995), highlighting the dependence of these 2 species upon krill, and supporting acoustic observations that krill concentrations in the Coronation Island region were low. Acoustic data further suggested that in the vicinity of Coronation Island, in contrast to the Willis Islands, high concentrations of small zooplankton did not prevail and that larger nektonic scatterers contributed most to regional faunal biomass (see Table 4 and Fig. 4). This observation is supported by the fact that at Seal Island in the South Shetlands (see Fig. 1), the nearest oceanographically similar location (Gordon \& Molinelli 1982) from which data are available, predator stomach content analyses indicate that in the 1993/94 season the proportion of fish in chinstrap penguin diets rose from a previous 4 season mean of 0.6 to $9 \%$ (CCAMLR 1995)

In the absence of detailed net haul analysis, predator diet composition has served as an alternate and effective sampling tool, providing some independent verification of the acoustically determined pelagic faunal composition in the vicinity of the Willis and Coronation Islands during a season characterised by an extreme paucity of krill. To our knowledge this is the first instance that such an integrated approach has been used to describe and quantify the relative contributions of discrete faunal classes to overall pelagic biomass, and the value of integrating predator/prey and acoustic studies to describe the composition of localised marine ecosystems is clearly demonstrated.
Acknowledgements. We acknowledge Dr David Socha, whose expertise in development of AVS-based software greatly aided analysis of the acoustic data reported here. We thank Dr John Croxall, Keith Reid and colleagues for generously providing the data from Willis and Signy Islands on predator diets and breeding performance in 1994, and Drs Peter Boveng, John Bengston and David Agnew for permission to include data on predators at Seal Island. Dr Inigo Everson and Alistair Murray offered invaluable advice on data analysis, and Dr Andy Wood assisted enormously with data management; Drs Julian Priddle and Roger Hewitt both made constructive comments on an early draft of this manuscript. We also thank the Master and crew of RRS 'James Clark Ross' cruise JR06.

\section{LITERATURE CITED}

Atkinson A (1990) The ecology of zooplankton around the island of South Georgia, Antarctica. PhD thesis, Council for National Academic Awards, British Antarctic Survey, Cambridge

Boyd IL, Croxall J, Lunn NJ, Reid K (1995) Population demography of Antarctic fur seals: the costs of reproduction and implications for life-histories. J Anim Ecol 64: 505-518

Brierley AS, Watkins JL (1995a) A comparison of acoustic targets at South Georgia and the South Orkneys during a season of profound krill scarcity. WG-EMM-95/74 CCAMLR, Hobart, Australia

Brierley AS, Watkins JL (1995b) An acoustic estimation of krill densities to the north of South Georgia in January 1994 WG-EMM-95/75 CCAMLR, Hobart, Australia

CCAMLR (1991) Report of the third meeting of the working group on krill. SC-CAMLR-X/4, Hobart, Australia

CCAMLR (1995) Index part 2. CEMP indices: tables of results 1995. WG-EMM-95/13 Rev. 1 CCAMLR, Hobart, Australia

Clay CS, Medwin H (1977) Acoustical oceanography: principles and applications. Wiley, New York

Clutter RI, Anraku M (1968) Avoidance of samplers in zooplankton sampling. In: Tranter DJ (ed) UNESCO monographs on oceanographic methodology, 2: zooplankton sampling. UNESCO Press, Paris, p 57-76

Croxall JP (1989) Use of indices of predator status and performance in CCAMLR fishery management. Sel Sci Pap CCAMLR Sci Com 1989, Hobart, Australia, p $353-365$

Croxall JP (1993) Diet. In: Laws RM (ed) Antarctic seals: research methods and techniques. Cambridge University Press, Cambridge, p 268-290

Croxall JP, McCann TS, Prince PA, Rothery P (1988) Reproductive performance of seabirds and seals at South Georgia and Signy Island, South Orkney Islands, 1976-1987: implications for Southern Ocean monitoring studies. In: Sahrhage D (ed) Antarctic Ocean and resources variability. Springer-Verlag, Berlin, p 261-285

Croxall JP, Prince PA, Reid K (in press) Dietary segregation of krill-eating South Georgia seabirds. J Zool

Croxall JP, Rothery P (1995) Population change in Gentoo penguins Pygoscelis papua at Bird Island, South Georgia: potential roles of adult survival, recruitment and deferred breeding. In: Dann P, Norman I, Reilly P (eds) Penguins, advances in research and management. Surrey Beatty \& Sons, Chipping Norton, NSW, p 26-38

Demer DA, Hewitt RP (1995) Bias in acoustic biomass estimates of Euphausia superba due to diel vertical migration. Deep Sea Res 42:455-475 
Everson I (1983) Variations in vertical distribution and density of krill swarms in the vicinity of South Georgia. Mem Natl Inst Polar Res, Spec Iss 27:84-92

Everson I, Miller DGM (1994) Krill mesoscale distribution and abundance: results and implications of research during the BIOMASS programme. In: El-Sayed SZ (ed) Southern Ocean ecology: the BIOMASS perspective. Cambridge University Press, Cambridge, p 129-143

FIBEX (1980) FIBEX acoustic survey design. BIOMASS Rep Ser 14

Foote KG (1987) Fish target strengths for use in echo integrator surveys. J Acoust Soc Am 83:981-987

Foote KG, Knudsen HP, Vestnes G, MacLennan DN, Simmonds EJ (1987) Calibration of acoustic instuments for fish density estimation: a practical guide. ICES Coop Res Rep 144

Gliwicz MZ (1986) Predation and the evolution of vertical migration in zooplankton. Nature 320:746-748

Godlewska M, KJusek K (1987) Vertical distribution and diurnal migrations of krill Euphausia superba Dana from hydroacoustical observations, SIBEX, December 1983/ January 1984. Polar Biol 8:17-22

Gordon AL, Molinelli EJ (1982) Suthern Ocean atlas. Colombia University Press, New York

Greene CH, Stanton TK, Wiebe PH, Mcclatchie S (1991) Acoustic estimates of Antarctic krill. Nature 349:110

Hewitt RP, Demer DA (1993) Dispersion and abundance of Antarctic krill in the vicinity of Elephant Island in the 1992 austral summer. Mar Ecol Prog Ser 99:29-39

Hovekamp S (1989) Avoidance of nets by Euphausia pacifica in Dubob Bay. J Plankton Res 11:907-924

Hunt GL, Heinemann D, Everson I (1992) Distributions and predator-prey interactions of Macaroni penguins, Antarctic fur seals, and Antarctic krill near Bird Island, South Georgia. Mar Ecol Prog Ser 86:15-30

Jolly GM. Hampton I (1990) A stratified random transect design for acoustic surveys of fish stocks. Can J Fish Aquat Sci $47: 1282-1291$

Kanda K, Takagi K, Seki Y (1982) Movement of the larger swarms of Antarctic krill Euphausia superba off Enderby Land during 1976-1977 season. J Tokyo Univ Fish 68: $25-42$

Kane JE (1966) The distribution of Parathemisto gaudichaudii (Guer) with observations of its life-history in the $0^{\circ}$ to $20^{\circ}$ sector of the Southern Ocean. 'Discovery' Rep 34:163-198

Liddle GM (1994) Interannual variation in the breeding biology of the Antarctic prion Pachyptila desolata at Bird Island, South Georgia. J Zool 234:125-139

Lishman GS (1985). The food and feeding ecology of Adélie penguins (Pygoscelis adeliae) and chinstrap penguins ( $P$. antarctica) at Signy Island, South Orkney Islands. J Zool 205:245-263

MacLennan DN, Simmonds EJ (1992) Fish and fisheries series, 5: fisheries acoustics. Chapman and Hall, London

Madureira LSP, Everson I, Murphy EJ (1993a) Interpretation of acoustic data at two frequencies to discriminate between Antarctic krill (Euphausia superba Dana) and other scatterers. J Plankton Res 15:787-802

Madureira LSP, Ward P. Atkinson A (1993b) Differences in backscattering strength determined at 120 and $38 \mathrm{kHz}$ for three species of Antarctic macroplankton. Mar Ecol Prog Ser 93:17-24

McClatchie S, Greene CH, Macaulay MC, Sturley DRM (1994) Spatial and temporal variability of Antarctic krill: implications for stock assessment. ICES J Mar Sci 51 $11-18$
Mitson RB, Simard Y. Goss C (1996) Use of a two-frequency algorithm to determine size and numbers of plankton in three widely spaced locations. ICES J Mar Scl 53:209-21.5

Morris DJ, Watkins JL, Ricketts C, Buchholz F, Priddle J (1988) An assessment of the merits of length and weight measurements of Antarctic krill Euphausia superba. Br Antarct Surv Bull 79:27-50

Murray AWA (1996) Comparison of geostatistical and random sample survey analyses of Antarctic krill acoustic data. ICES J Mar Sc1 53:415-421

Murray AWA, Watkins JL, Bone DG (1995) A biological acoustic survey in the marginal ice edge zone of the Bellingshausen Sea. Deep Sea Res 42:1159-1175

Payne RW, Lane PW. Digby PGN, Harding SA, Leech PK, Morgan GW, Todd AW, Thompson R, Tunnicliffe Wilson G, Welham SI, White RP (1993) Genstat 5 Release 3 reference manual. Oxford University Press, Oxford

Petitgas P (1993) Geostatistics for fish stock assessments: a review and an acoustic application. ICES J Mar Sci 50: 285-298

Petitgas P, Prampart A (1993) EVA (Estimation VAriance): a geostatistical software on IBM-PC for structure characterIzation and vanance computation. ICES CM 1993/D:65

Priddle J, Croxall JP, Everson I, Heywood RB, Murphy EJ, Prince PA, Sear CB (1988) Large-scale fluctuations in distribution and abundance of krill-a discussion of possible causes. In: Sahrhage D (ed) Antarctic Ocean and resources variability. Springer-Verlag, Berlin, p 169-182

Reid K, Arnould JPY (1996) The diet of Antarctic fur seals Arctocephalus gazella during the breeding season at South Georgia. Polar Biol 16:105-114

Rogers A.D (1994) The biology of seamounts. Adv Mar Biol 30: $305-350$

Siegel $V$ (1988) A concept of seasonal variation of krill (Euphausia superba) distribution and abundance west of the Antarctic peninsula. In: Sahrhage D (ed) Antarctic ocean and resources variability. Springer-Verlag, Berlin, p $219-230$

Siegel V, Loeb V (1995) Recruitment of Antarctic krill Euphausia superba and possible causes for its variability. Mar Ecol Prog Ser 123:45-56

Simmonds EJ, Williamson NJ, Gerlotto G, Aglen S (1992) Acoustic survey design and analysis procedure: a comprehensive review of current practice. ICES Coop Res Rep 187

Simrad (1992) Simrad EK500 scientific echo sounder, P2170E edn. Simrad, Horten

Socha DG, Watkins JL, Brierley AS (1996) A visualisationbased post-processing system for analysis of acoustic data ICES J Mar Sci 53:335-338

Trathan P, Croxall JP, Murphy EJ (1996) Dynamics of Antarctic penguin populations in relation to the annual variability in sea ice distribution. Polar Biol 16:321-330

Trathan PN, Everson I (1994) Status of the FIBEX acoustic data from the West Atlantic. CCAMLR Sci 1:35-48

Trathan PN, Everson I, Miller DGM, Watkins JL, Murphy EJ (1995) Krill biomass in the Atlantic. Nature 373:201-202

Trivelpiece WZ, Trivelpiece SG, Volkman NJ (1987) Ecological segregation of Adélie, Gentoo and chinstrap penguins at King George Island, Antarctica. Ecology 68:351-361

Veit RR, Silverman ED, Everson I (1993) Aggregation parameters of pelagic predators and their principal prey, Antarctic krill, near South Georgia. J Anim Ecol 62: $551-564$

Watkins JL (1986) Variations in the size of Antarctic krill, Euphausia superba Dana, in small swarms. Mar Ecol Prog Ser 31:67-73 
Watkins JL, Brierley AS (1996) A post-processing technique to remove background noise from echo-integration data. ICES J Mar Sci 53:339-344

Watkins JL, Brierley AS, Murray AWA, Goss C (1995) A summary of software problems encountered with the Simrad EK500 system. WG-EMM-95/73 CCAMLR, Hobart, Australia

Watkins JL, Morris DJ, Ricketts C, Murray AWA (1990) Sampling biological characteristics of krill: effect of heterogeneous nature of swarms. Mar Biol 107:409-415

This article was submitted to the editor
Watkins JL, Morris DJ, Ricketts C, Priddle J (1986) Differences between swarms of Antarctic krill and some implications for sampling krill populations. Mar Biol 93: $137-146$

White $\mathrm{MG}$, Conroy JWH (1975) Aspects of competition between pygoscelid penguins at Signy Island, South Orkney Islands. Ibis 117:371-373

Wiebe PH, Boyd SH, Davis BM, Cox JL (1982) Avoidance of towed nets by the euphausiid Nematoscelis megalops. Fish Bull US 80:75-91

Manuscript first received: October 9, 1995

Revised version accepted: April 3, 1996 